\title{
Shannon Entropy and $K$-Means Method for Automatic Diagnosis of Broken Rotor Bars in Induction Motors Using Vibration Signals
}

\author{
David Camarena-Martinez, ${ }^{1}$ Martin Valtierra-Rodriguez, ${ }^{2}$ Juan P. Amezquita-Sanchez, \\ David Granados-Lieberman, ${ }^{3}$ Rene J. Romero-Troncoso, ${ }^{1}$ and Arturo Garcia-Perez ${ }^{1}$ \\ ${ }^{1}$ División de Ingenierías, Universidad de Guanajuato, Campus Irapuato-Salamanca, Carretera Salamanca-Valle de Santiago \\ Km 3.5 + 1.8, Comunidad de Palo Blanco, 36885 Salamanca, GTO, Mexico \\ ${ }^{2}$ Facultad de Ingeniería, Universidad Autónoma de Querétaro, Campus San Juan del Río, Río Moctezuma 249, \\ Col. San Cayetano, 76807 San Juan del Río, QRO, Mexico \\ ${ }^{3}$ Departamento de Ingeniería Electromecánica, Instituto Tecnológico Superior de Irapuato, Carretera Irapuato-Silao Km 12.5, \\ Colonia El Copal, 36821 Irapuato, GTO, Mexico \\ Correspondence should be addressed to Arturo Garcia-Perez; agarcia@hspdigital.org
}

Received 2 June 2016; Revised 1 August 2016; Accepted 21 August 2016

Academic Editor: Lu Chen

Copyright (C) 2016 David Camarena-Martinez et al. This is an open access article distributed under the Creative Commons Attribution License, which permits unrestricted use, distribution, and reproduction in any medium, provided the original work is properly cited.

\begin{abstract}
For industry, the induction motors are essential elements in production chains. Despite the robustness of induction motors, they are susceptible to failures. The broken rotor bar (BRB) fault in induction motors has received special attention since one of its characteristics is that the motor can continue operating with apparent normality; however, at certain point the fault may cause severe damage to the motor. In this work, a methodology to detect BRBs using vibration signals is proposed. The methodology uses the Shannon entropy to quantify the amount of information provided by the vibration signals, which changes due to the presence of new frequency components associated with the fault. For automatic diagnosis, the $K$-means cluster algorithm and a decisionmaking unit that looks for the nearest cluster through the Euclidian distance are applied. Unlike other reported works, the proposal can diagnose the BRB condition during startup transient and steady state regimes of operation. Additionally, the proposal is also implemented into a field programmable gate array in order to offer a low-cost and low-complex online monitoring system. The obtained results demonstrate the proposal effectiveness to diagnose half, one, and two BRBs.
\end{abstract}

\section{Introduction}

Inductions motors are widely used in many applications because of their easy maintenance, ruggedness, low cost, versatility, and ease control [1]. During their service life, they are subject to unavoidable failures as a result of mechanical, environmental, thermal, and electrical stresses [2]. These faults such as bearing faults, air gap eccentricity, and broken rotor bars (BRBs) can yield a reduction on production, product quality, and an increase on costs, besides being a hazard for people and machinery [3]. Among the different faults that can occur in induction machines, BRB is a silent failure that allows operating the motor with apparent normality, but it can cause an excessive vibration, a change in current consumption, and higher thermal stress with catastrophic consequences if the situation is not solved at early stages $[4,5]$. In this regard, condition monitoring equipment has become an essential tool in many industrial areas. Yet, this task is very challenging because depending on the application the motor may be subject to transient and/or steady (nominal) regimes of operation, which changes its mechanical and electrical conditions by affecting and limiting the performance of equipment that only operates in a specific regime. From this point of view, an online and real-time monitoring system for an early detection of BRB in transient and steady regimes is a needed equipment in many industrial areas, since it will allow 
scheduling maintenance operations in order to minimize its negative impact as well as saving time and money.

During the last decade, several vibration and current analysis-based processing techniques for BRB detection have been proposed. The conventional signal processing technique used to perform this task is the fast Fourier transform (FFT) [6-8]. However, it is limited in its capability for extracting features from signals that exhibit nonlinear and nonstationary characteristics, besides being susceptible to noise, making a correct identification of features related to the BRB fault difficult [9]. More recently, other powerful signal processing techniques, such as multiple signal classification (MUSIC) algorithm [10, 11], wavelet transform (WT) [9, 12-16], Empirical mode decomposition combined with Hilbert transform known as Hilbert-Huang transform (HHT) [16], and WignerVille distribution (WVD) [17], have been used for BRB detection. Nevertheless, although prominent results have been obtained, the aforementioned signal processing techniques present some unresolved difficulties. For instance, MUSIC requires a priori knowledge of the interest frequencies and consumes significant computational resources [11]. The WT capabilities are significantly degraded in noisy signals, and the mother wavelet has to be appropriately chosen to obtain reliable results [4]. On the other hand, the WVD introduces cross-term interference in the estimated signal components, which inhibits the efficient estimation of the instantaneous frequencies, besides suffering aliasing problem [18]. The HHT suffers from the mode mixing effect, which means that waves with the same frequency are assigned to different intrinsic mode functions, affecting the accurate estimation of the instantaneous frequencies. In general, many advantages and disadvantages of the aforementioned techniques may be further discussed; yet, from a monitoring equipment viewpoint, two aspects become important. The first one is the performance capabilities; it means that the equipment does not degrade its performance when it analyzes transient or stationary signals. This desirable feature may be achieved either using a nonsusceptible signal processing technique or using different techniques for each scenario. The second one is the complexity since it may compromise the online analysis if low-end digital signal processors are used. In this regard, it would be desirable to have a signal processing algorithm with both the ability of identifying suitable and reliable features of signals for identifying BRB fault in different operating states and a low complexity for online analysis.

Similar to signal processing techniques, the classification algorithms play an important role in the automatic diagnosis of faults [19]. Different classification techniques such as neural networks [20, 21] and fuzzy logic [22, 23] have been successfully applied for monitoring the condition of induction motors. Unfortunately, the neural networks and other conventional artificial intelligent techniques require enough samples and have limitations on generalization of results in models that can overfit the samples [13]. Therefore, having in mind that online monitoring equipment may require low-complexity procedures, a classification algorithm with a suitable accuracy without the need of complicated processing, that requires a small number of samples, and, mainly, that allows developing a methodology capable of identifying several faults in different scenarios is a desirable tool. A promising classification technique is the $K$-means algorithm. It is a well-known signal classification technique that has been successfully utilized in many applications such as neuroscience [24], structural engineering [25], and mechanics [26]. This approach provides a high accuracy and good generalization for a small number of features; besides its computational cost during and after its design is relatively low.

In this work, a methodology to detect automatically the BRB fault in induction motors using vibration signals is presented. The proposal considers the analysis of both the startup transient and the steady state of operation, which is very important since the induction motor may be subject to both scenarios in real applications; besides, an implementation into a field programmable gate array (FPGA) is also presented as system-on-chip (SoC) solution. This allows offering a system for online and continuous monitoring. Regarding the BRB condition, half, one, and two bars are considered. For the analysis, the Shannon entropy is used as a measure of the information contained in the vibration signals. This information presents changes associated with the fault. Then, the obtained entropy values are classified for automatic diagnosis using the $K$-means algorithm. The results show that the proposal can be a low-complex and suitable tool for BRB detection in both the startup transient and the steady state of operation.

\section{Theoretical Background}

In this section, the two main topics of the proposed methodology are briefly described.

2.1. Entropy. In information theory, entropy describes how much information about the data randomness is provided by a signal or event [27]. It has been used in image processing [28], in gearbox fault detection [29], in structural health monitoring [30], for analysis of electroencephalogram signals to diagnose the patient's clinical condition [31], and in fault motor diagnosis [15, 19, 32] among others. In particular, Shannon entropy, named after Claude Shannon, of a random signal $X$ with $N$ possible outcomes $x_{0}, x_{1}, x_{2}, \ldots, x_{N-1}$ and with a probability of $p\left(x_{i}\right)$ can be computed as follows:

$$
H(X)=-\sum_{i=0}^{N-1} p\left(x_{i}\right) \log _{2}\left[p\left(x_{i}\right)\right],
$$

where it is bounded by $0 \leq H(X) \leq \log _{2}(N)$.

Due to the number of applications and to the requirements of processing time, a hardware processing unit based on FPGA for entropy estimation is presented by [33], where a simplified mathematical expression is given as follows:

$$
E(X)=\log _{2}(N)-\left(\frac{1}{N}\right) \sum_{i=0}^{N-1} r_{i} \log _{2}\left(r_{i}\right)
$$

where $r_{i}$ is the incidence rate or histogram of a signal $X$; therefore, $p\left(x_{i}\right)$ is $r_{i} / N$. In general, this expression follows the structure shown in Figure 1. 

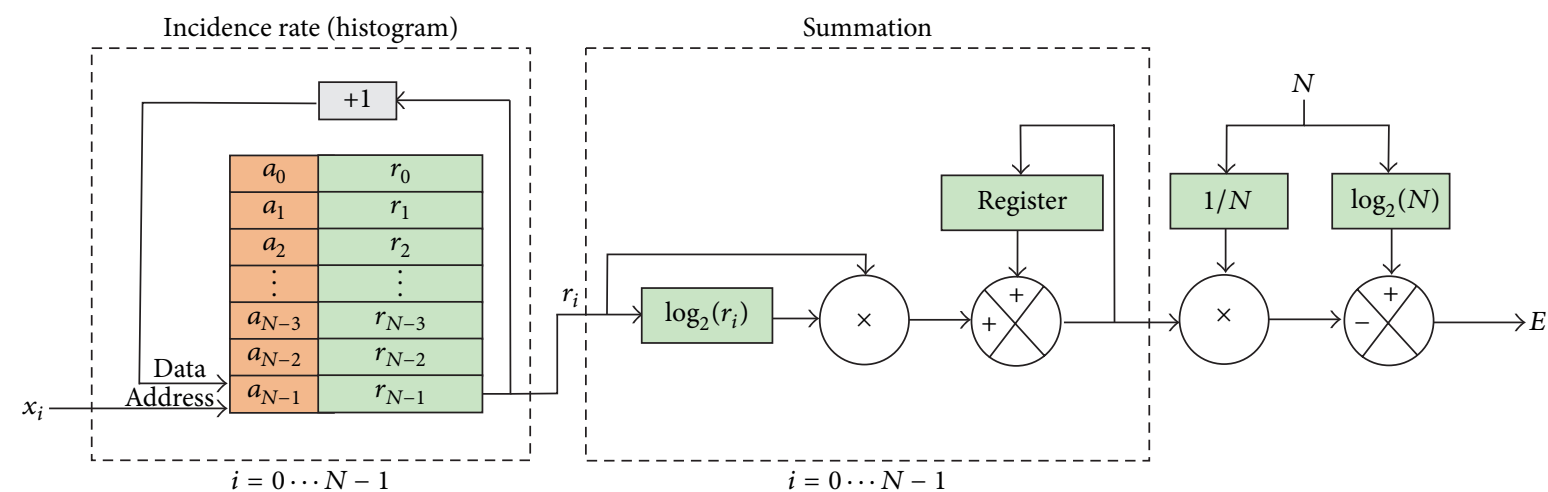

FIGURE 1: General structure for the entropy processor.

2.2. K-Means. In general, cluster analysis consists of creating groups of objects with similar features [34]. It implies that an object has to comply or has certain features for belonging to a specific group. In this regard, a classification task for unseen data can be carried out by looking for a group that fits better.

$K$-means is a simple and popular algorithm to solve clustering problems. The goal of the algorithm is to divide a data set $Y=\left\{y_{1}, y_{2}, \ldots, y_{N}\right\}$ with $N$ data into $k$ clusters. The number of clusters is fixed a priori. The objective function based on squared Euclidian distances is calculated as follows [35]:

$$
F\left(m_{1}, \ldots, m_{k}\right)=\sum_{i=1}^{k} \sum_{j=1}^{M_{i}}\left\|y_{i j}-m_{i}\right\|^{2},
$$

where $M_{i}$ is the number of objects of each $i$ th cluster, $y_{i j}$ is the $j$ th object of the $i$ th cluster, and $m_{i}$ is the center of the $i$ th cluster, which is defined as

$$
m_{i}=\frac{1}{M_{i}} \sum_{j=1}^{M_{i}} y_{i j}, \quad i=1, \ldots, k .
$$

The overall procedure is summarized as follows [34]: (1) select randomly the initial positions of the $K$-centroids; (2) assign the data set $Y$ to the closest centroid; (3) relocate iteratively the $K$-centroids in order to minimize the objective function. It is worth noting that $K$-means algorithm is sensitive to the initial $k$ clusters; however, it can be applied a number of times in order to find either the global objective function minimum or an acceptable error.

\section{Proposed Methodology}

The overall work is carried out in two stages, design and implementation, as shown in Figure 2.

3.1. Design Stage. In this stage, the extraction of the $K$ centroids for automatic diagnosis of BRBs in induction motors is carried out and shown in Figure 2(a). First, a set of vibration signals for each induction motor condition, healthy (HLT), half broken rotor bar (HBRB), one broken rotor bar (1BRB), and two broken rotor bars (2BRB), are acquired during the startup transient and the steady state. The vibration signals are measured through a triaxial accelerometer $(A x$, $A y$, and $A z$ ). Second, the Shannon entropy of each signal is computed using (2). Third, the $K$-means clustering algorithm is applied several times in order to look for the best clusters for each induction motor condition. The overall analysis is carried out using Matlab software. It is found, as will be discussed in the next sections, that the entropy values, Ex and $E z$, present the best classification results; therefore, the $K x$ and $K z$ centroids for each cluster are selected as baseline for each condition.

3.2. Implementation Stage. In order to offer an online diagnosis tool, the proposed methodology is implemented into an FPGA as shown in Figure 2(b). First, the $K$-centroids for startup transient and steady state of each induction motor condition are stored into read-only memories, which are chosen by the user according to the actual motor operation. Second, the entropy values are estimated using the entropy processor, which follows the digital structure presented in Figure 1. Third, the Euclidian distances from entropy values to each cluster are computed using the coordinate rotation digital computer (CORDIC) algorithm [36]. Finally, a decisionmaking unit looking for the nearest cluster determines the induction motor condition.

\section{Experimentation and Results}

4.1. Design Stage. The vibration signals acquired for each induction motor condition during startup transient and steady state are presented in Figures 3 and 4, respectively. The total number of tests for each condition is 20 , giving a total of 160 tests; their entropy values are shown in Figure 5. These values are bounded by the mean $(\mu)$ and \pm 3 standard deviation $(\sigma)$ in order to ensure an occurrence of $99.7 \%$ [33]; Table 1 presents the numerical values. The best $K$-means clusters are obtained using $E x$ and $E z$ since they offer more nonoverlapped patterns. The clusters are shown in Figure 6, where the Voronoi cells are used. The estimated values for the $K x$ and $K z$ centroids are summarized in Table 2.

4.2. Experimental Setup. The experimental setup used to test the proposal is shown in Figure $7(\mathrm{a})$. The induction 


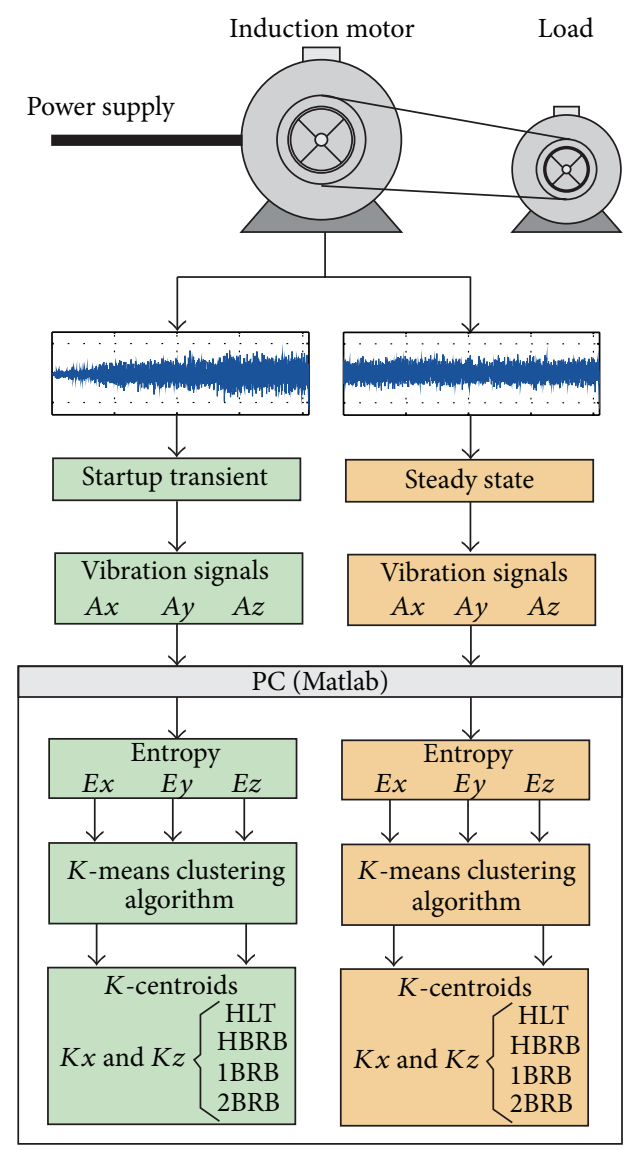

(a)

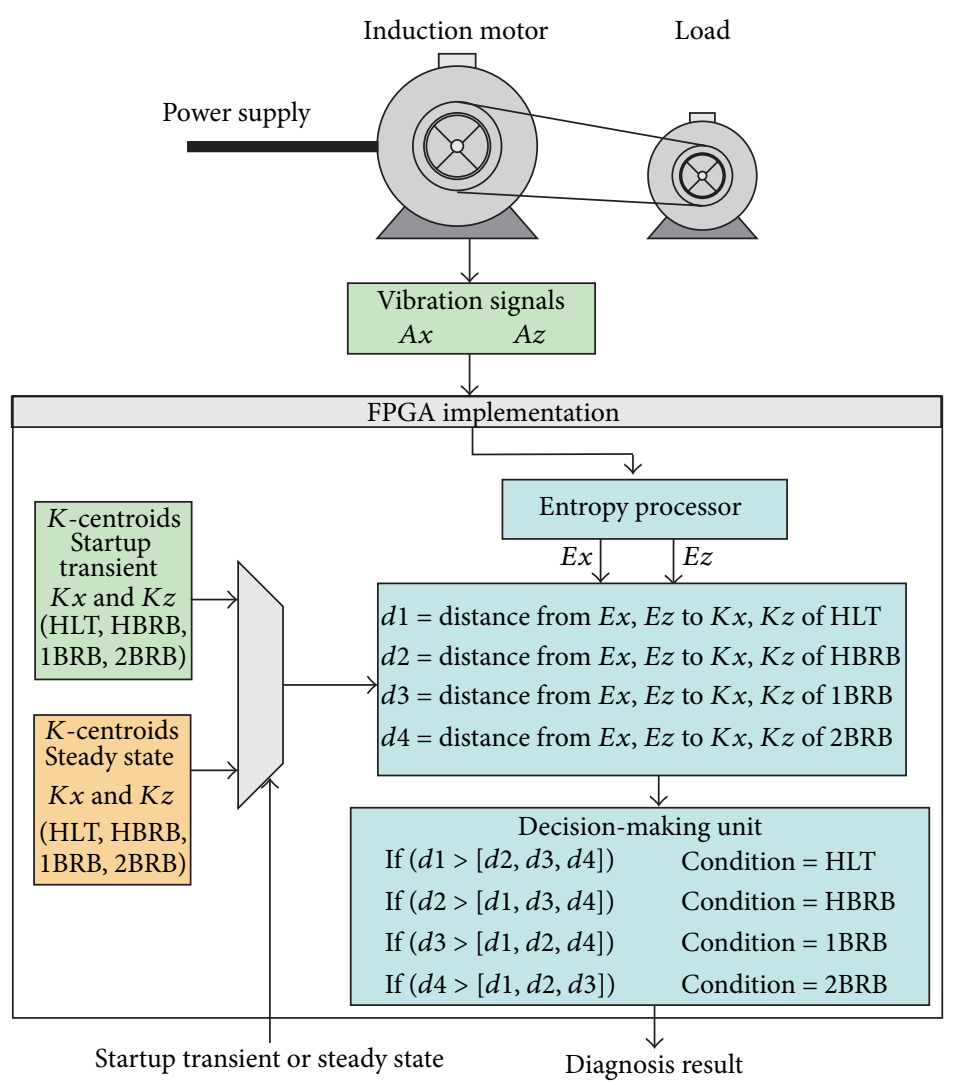

(b)

FIgURE 2: Proposed methodology: (a) design stage and (b) implementation stage.

TABLE 1: Entropy values.

\begin{tabular}{|c|c|c|c|c|c|c|}
\hline \multirow{3}{*}{ Condition } & \multicolumn{6}{|c|}{ Entropy $(\mu, \sigma)$} \\
\hline & \multicolumn{3}{|c|}{ Startup transient } & \multicolumn{3}{|c|}{ Steady state } \\
\hline & $E x$ & Ey & $E z$ & $E x$ & Ey & $E z$ \\
\hline HLT & $8.7530,0.0416$ & $9.1929,0.0484$ & $9.0489,0.0644$ & $8.6236,0.715$ & $9.4280,0.0526$ & $9.0940,0.0941$ \\
\hline HBRB & $8.1024,0.0445$ & $8.9868,0.0487$ & $8.7272,0.0566$ & $7.8979,0.0528$ & $9.0849,0.0544$ & $8.6348,0.0596$ \\
\hline $1 \mathrm{BRB}$ & $9.0152,0.0716$ & $9.3918,0.0345$ & $9.7105,0.0345$ & $8.4532,0.1763$ & $8.9832,0.0927$ & $9.8297,0.0927$ \\
\hline $2 \mathrm{BRB}$ & $9.1787,0.0511$ & $9.4535,0.0430$ & $9.2498,0.0589$ & $8.8621,0.0629$ & $9.6350,0.0647$ & $9.2908,0.0484$ \\
\hline
\end{tabular}

TABLE 2: Values of the $K$-centroids.

\begin{tabular}{lcccc}
\hline & \multicolumn{4}{c}{$K$-centroids } \\
Induction motor condition & Startup transient & \multicolumn{2}{c}{ Steady state } \\
& $K x$ & $K z$ & $K x$ & $K z$ \\
\hline HLT & 8.7530 & 9.0489 & 8.6118 & 9.0811 \\
HBRB & 8.1024 & 8.7272 & 7.8979 & 8.6348 \\
lBRB & 9.0152 & 9.7105 & 8.4532 & 9.8297 \\
2BRB & 9.1787 & 9.2498 & 8.8614 & 9.2930 \\
\hline
\end{tabular}

motor (model WEG 00136APE48T) has two poles and 28 bars. It is fed with $220 \mathrm{Vac}$ at $60 \mathrm{~Hz}$. The mechanical load is provided by an ordinary alternator. The 3-axis vibration signal is measured by an accelerometer model LIS3L0AS4 placed on the top of the induction motor as shown in Figure 7(b). A 12-bit 4-channel analog to digital converter model ADS7841 is used for analog to digital conversion. The data acquisition system has a sampling frequency of $1500 \mathrm{~Hz}$ and captures 4096 samples (2.73 s), which is enough to capture the startup transient; the same time is used for the steady state. Figure 7(c) shows the four rotor conditions; the $\mathrm{BRB}$ condition is artificially created by drilling half, one, and two bars in the rotor without damaging the rotor shaft. The instrument in based on a proprietary Spartan 3E XC3S1600E FPGA with a frequency operation of $48 \mathrm{MHz}$; the FPGA resource utilization for the proposed methodology appears in Table 3. It is observed that it has a low consumption since a 

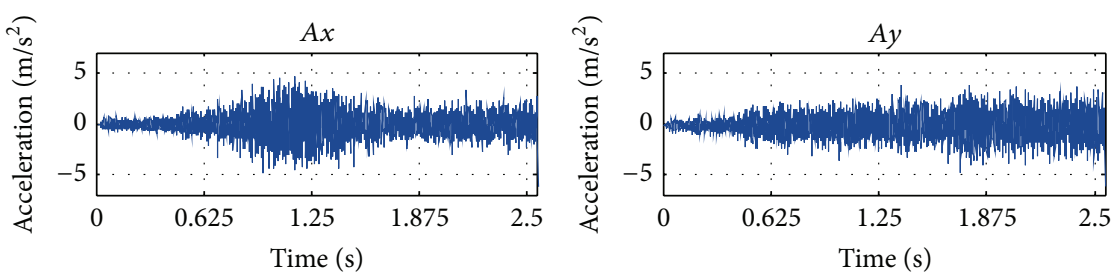

(a)
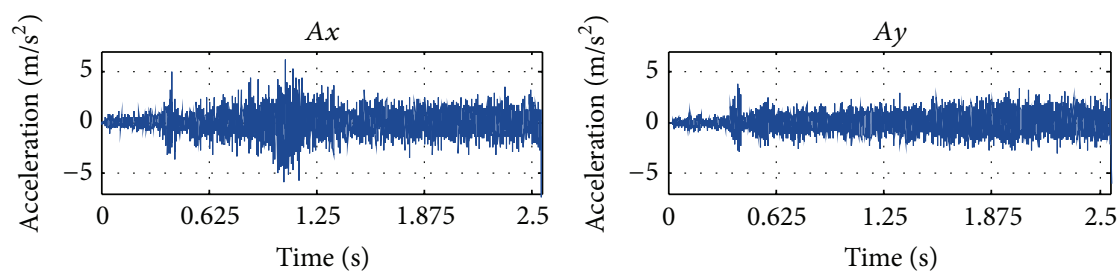

(b)
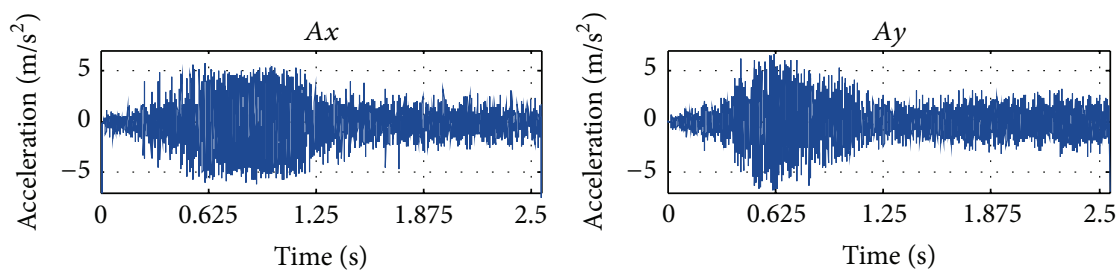

(c)
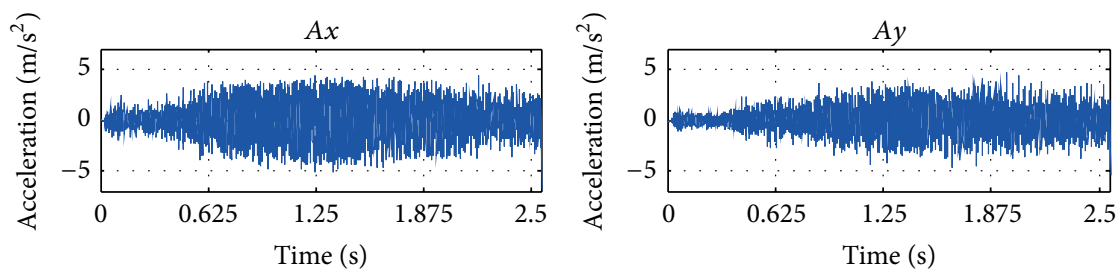
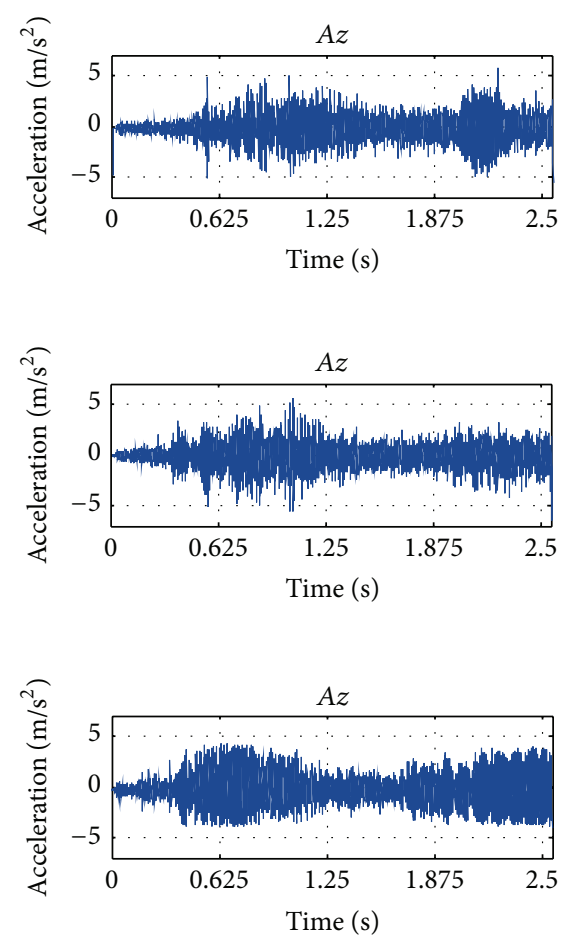

(d)

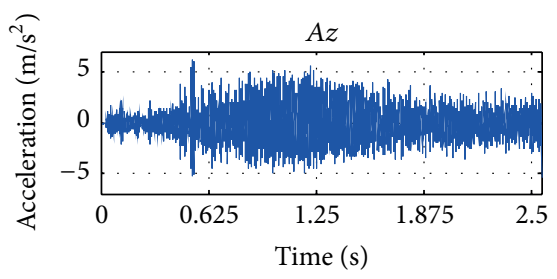

Figure 3: Vibration signals for startup transient: (a) HLT, (b) HBRB, (c) 1BRB, and (d) 2BRB.

TABLE 3: FPGA resources.

\begin{tabular}{lccc}
\hline & Available & Used & Percentage (\%) \\
\hline Programmable logic & 29504 & 1870 & 6.33 \\
LUTs & 29504 & 3445 & 11.67 \\
Multipliers & 36 & 2 & 5.55 \\
Clock cycles & & 57632 & \\
\hline
\end{tabular}

maximum of $11.67 \%$ is obtained; besides, the computational cost is also low since 57632 clock cycles $(1.2 \mathrm{~ms})$ are required to compute the final result. The overall system is tested 20 times for each motor condition. Tables 4 and 5 present the obtained classification results for startup transient and steady state, respectively. The correct results are located in the diagonals (highlighted in bold). Regarding the startup transient results, most the cases present an effectiveness of $100 \%$, which means that, of the 20 actual HLT conditions, the system classifies 20 HLT conditions. A mistake for HBRB is obtained; yet, it is a positive false since it is classified as 1BRB. On the other hand, the classification results for steady state regimen have $100 \%$ of effectiveness in all cases.
TABLE 4: Classification results for startup transient tests (confusion matrix).

\begin{tabular}{lccccc}
\hline $\begin{array}{l}\text { Induction } \\
\text { motor } \\
\text { condition }\end{array}$ & HLT & HBRB & 1BRB & 2BRB & $\begin{array}{c}\text { Percentage of } \\
\text { effectiveness } \\
(\%)\end{array}$ \\
\hline HLT & $\mathbf{2 0}$ & 0 & 0 & 0 & 100 \\
HBRB & 0 & $\mathbf{1 9}$ & 1 & 0 & 95 \\
1BRB & 0 & 0 & $\mathbf{2 0}$ & 0 & 100 \\
2BRB & 0 & 0 & 0 & $\mathbf{2 0}$ & 100 \\
\hline
\end{tabular}

Finally, it is worth noting that different vibration levels generated by other faults, neighboring equipment, and uncontrolled conditions can be induced in the motor frame, which will modify the vibration patterns shown in Figure 5 and, as a consequence, the performance of the classification algorithm; in this regard, new calibrations in known conditions will be required.

4.3. Discussion. Table 6 summarizes a performance comparison of the proposed method against recently reported 

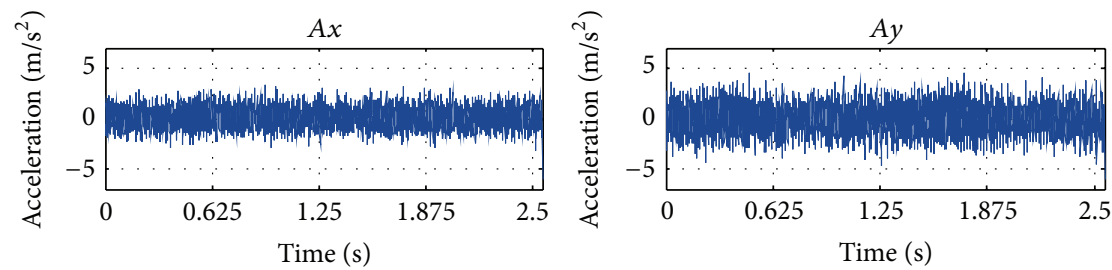

(a)
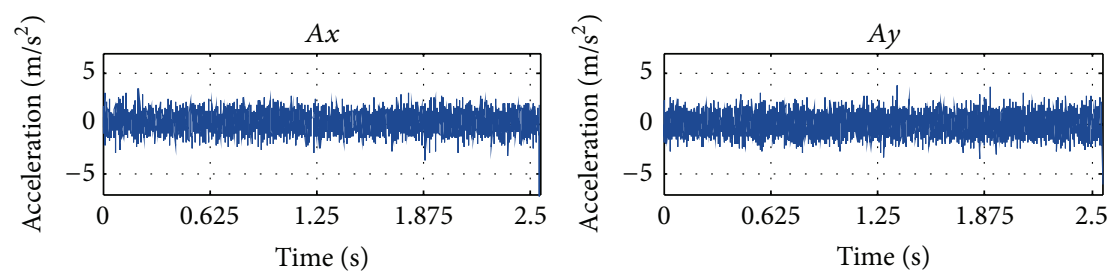

(b)
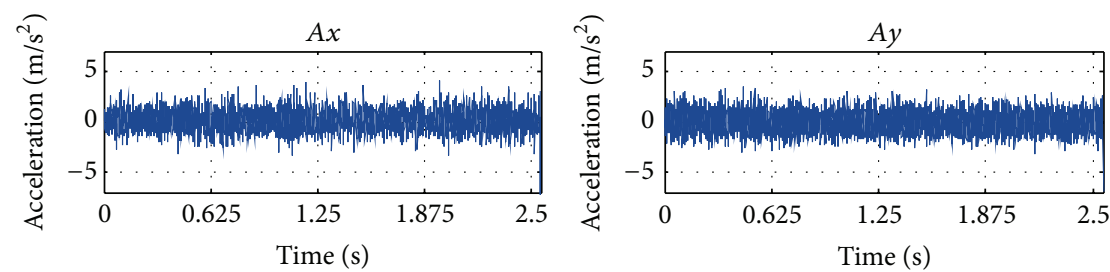

(c)

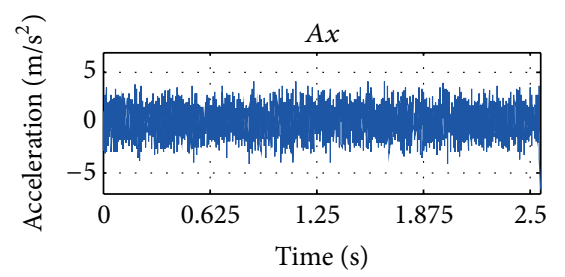

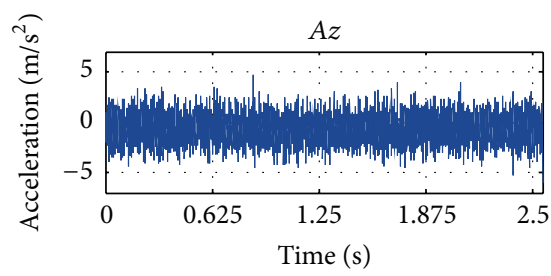
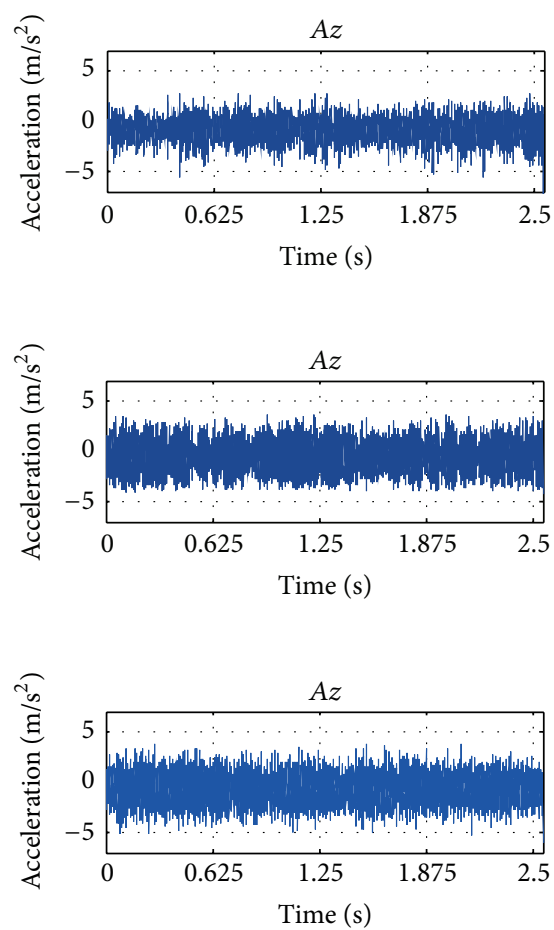

(d)

FIgURE 4: Vibration signals for steady state: (a) HLT, (b) HBRB, (c) 1BRB, and (d) 2BRB.
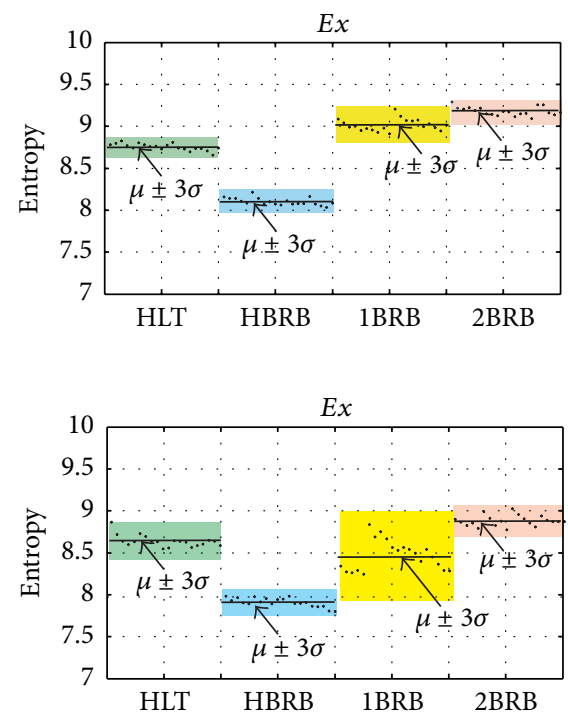

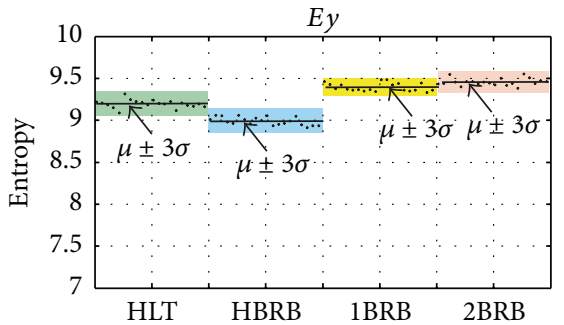

(a)
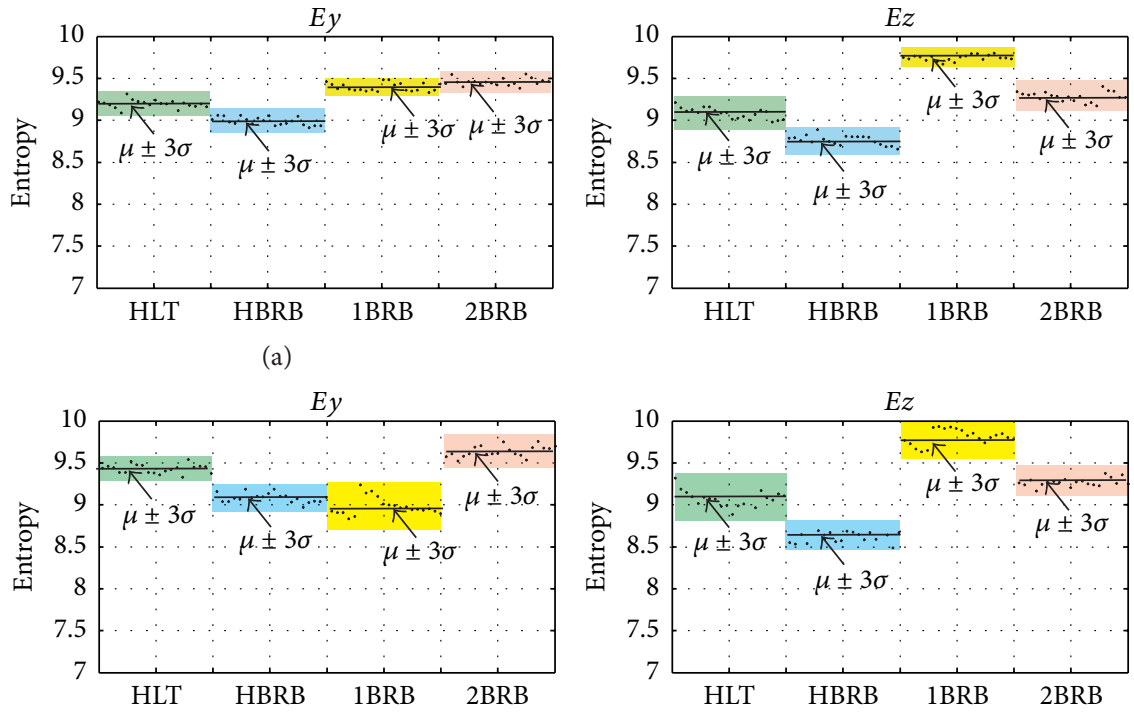

(b)

FIGURE 5: Entropy values for (a) startup transient tests and (b) steady state tests. 


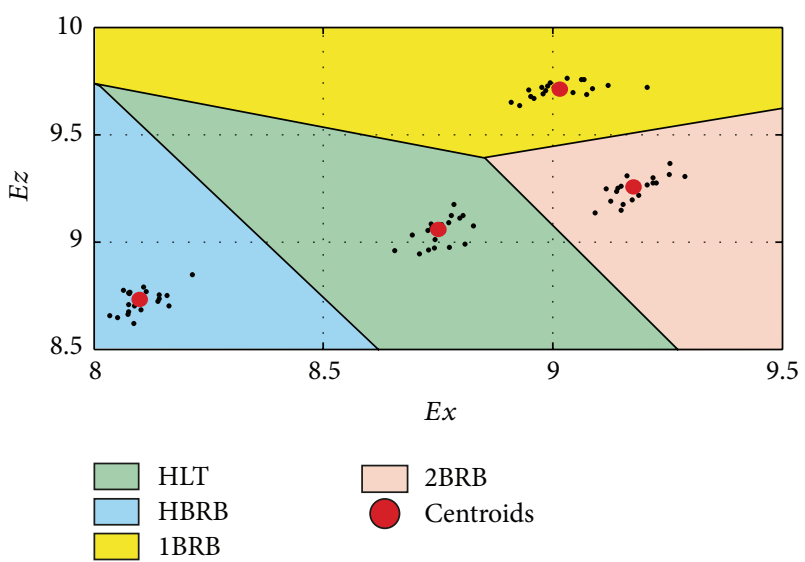

(a)

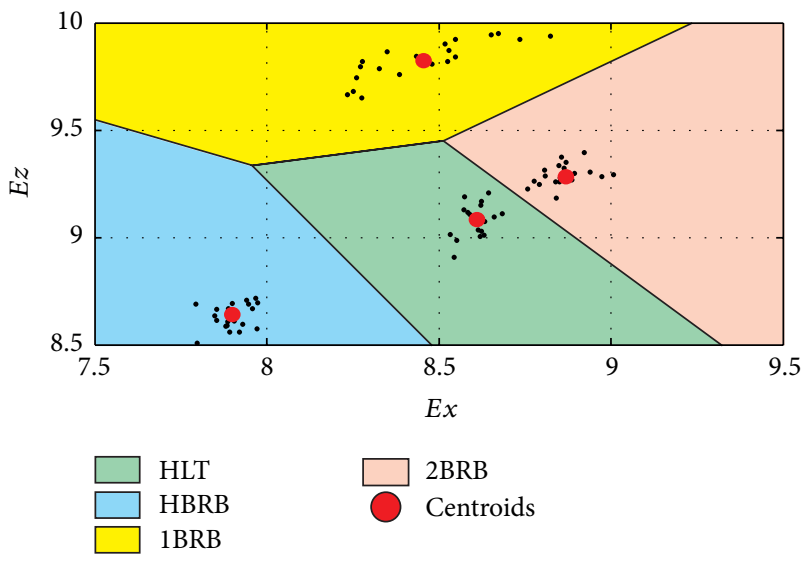

(b)

FIGURE 6: $K$-means clusters: (a) startup transient and (b) steady state.

TABLE 5: Classification results for steady state tests (confusion matrix).

\begin{tabular}{lccccc}
\hline $\begin{array}{l}\text { Induction } \\
\text { motor } \\
\text { condition }\end{array}$ & HLT & HBRB & 1BRB & 2BRB & $\begin{array}{c}\text { Percentage of } \\
\text { effectiveness } \\
(\%)\end{array}$ \\
\hline HLT & $\mathbf{2 0}$ & 0 & 0 & 0 & 100 \\
HBRB & 0 & $\mathbf{2 0}$ & 0 & 0 & 100 \\
1BRB & 0 & 0 & $\mathbf{2 0}$ & 0 & 100 \\
2BRB & 0 & 0 & 0 & $\mathbf{2 0}$ & 100 \\
\hline
\end{tabular}

works in literature, where parameters such as methodology applied, analyzed state, and the percentage of effectiveness are considered. From Table 6, it is clear that the proposed methodology can detect the presence of BRB with high accuracy in both states of induction motor. Unlike other reported works [37-42], the proposal considers HBRB in both states. Although HBRB detection, in both states, has been considered in [5], the proposal outperforms in several cases the effectiveness for diagnosing the induction motor condition, which makes it more attractive for industrial applications. Further, it is important to mention that the proposal presents two essential characteristics: (1) the automatic

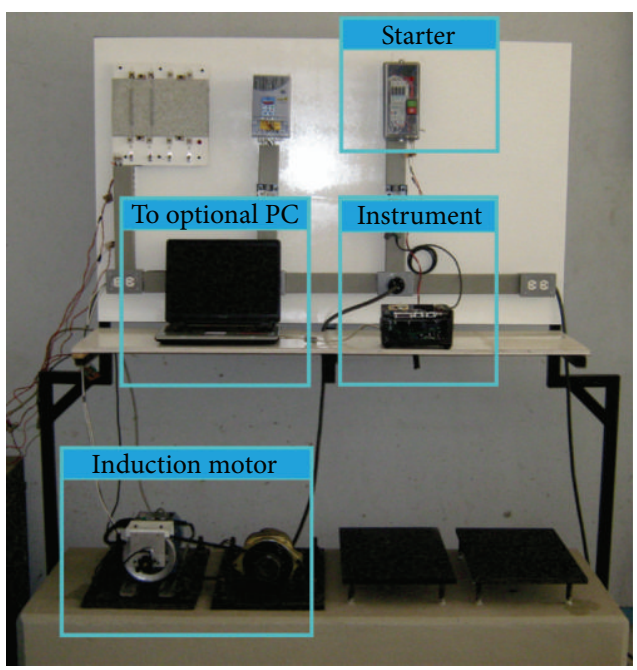

(a)

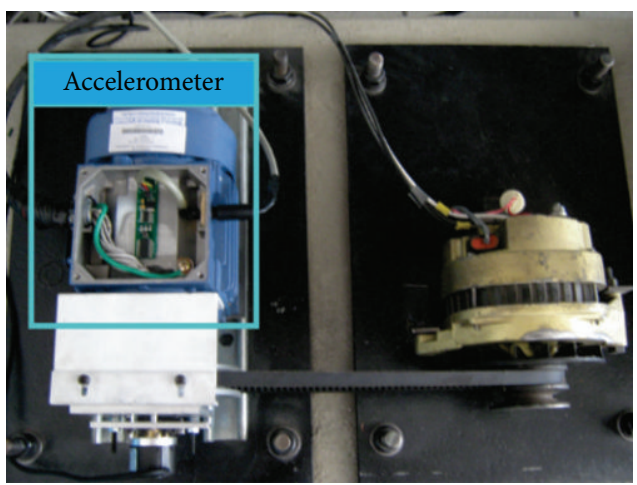

(b)
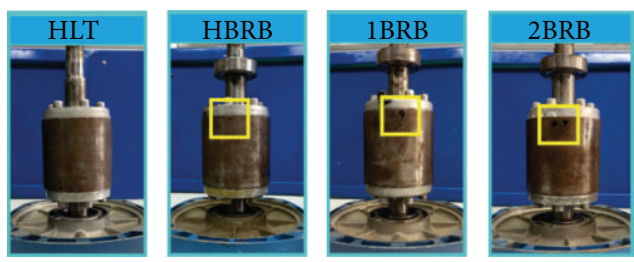

(c)

FIgURE 7: Experimentation: (a) experimental setup, (b) top view accelerometer, and (c) rotors.

identification of different grades of severity of broken bar faults and (2) the use of a single-parameter, which reduces the complexity and computational load. In addition, the designed FPGA implementation offers a low-cost and a real-time solution for online monitoring of induction motor condition.

\section{Conclusions}

In this work, a methodology based on Shannon entropy and $K$-means clustering algorithm for automatic diagnosis of BRBs during the startup transient and steady state is proposed. It allows diagnosing three severities of damage, HBRB, 1BRB, and 2BRB, as well as the HLT condition. Although a triaxial accelerometer to measure $A x, A y$, and 
TABLE 6: Results and characteristics of previous works and of the proposed work.

\begin{tabular}{|c|c|c|c|c|c|c|}
\hline \multirow{2}{*}{ Work } & \multirow{2}{*}{ Applied methodology } & \multirow{2}{*}{$\begin{array}{l}\text { Analyzed } \\
\text { state }\end{array}$} & \multicolumn{4}{|c|}{ Effectiveness (\%) } \\
\hline & & & HLT & HBRB & $1 \mathrm{BRB}$ & MBRB \\
\hline Matić et al. [37] & $\begin{array}{l}\text { (1) Feature selection through Hilbert transform. } \\
\text { (2) Fault diagnosis classification through support vector } \\
\text { machine. }\end{array}$ & Steady & 100 & - & 100 & - \\
\hline Da Silva et al. [38] & $\begin{array}{l}\text { (1) Feature selection through time-stepping finite-element } \\
\text { simulations. } \\
\text { (2) Fault diagnosis classification through a Bayesian classifier. }\end{array}$ & Steady & 100 & - & 100 & $100^{3,5}$ \\
\hline $\begin{array}{l}\text { Georgoulas et al. } \\
\text { [39] }\end{array}$ & $\begin{array}{l}\text { (1) Extraction features by means of complex empirical mode } \\
\text { decomposition. } \\
\text { (2) Fault diagnosis classification through hidden Markov } \\
\text { models. }\end{array}$ & Transient & 100 & - & 100 & $100^{2}$ \\
\hline Keskes et al. [40] & $\begin{array}{l}\text { (1) Stationary Wavelet Packet transform for statistical feature } \\
\text { extraction. } \\
\text { (2) Fault diagnosis classification through improved support } \\
\text { vector machine. }\end{array}$ & Steady & 100 & - & 99 & $99^{2}$ \\
\hline $\begin{array}{l}\text { Rangel-Magdaleno } \\
\text { et al. [41] }\end{array}$ & $\begin{array}{l}\text { (1) Mathematical morphology. } \\
\text { (2) Spectral analysis for identification of frequency } \\
\text { components related to the fault using FFT. } \\
\text { (3) Amplitude analysis from estimated spectrum for } \\
\text { statistical feature extraction. } \\
\text { (4) Fault diagnosis classification through a decision tree. }\end{array}$ & Steady & 95 & - & 95 & $95^{2}$ \\
\hline Menacer et al. [42] & $\begin{array}{l}\text { (1) Spectral analysis using discrete wavelet transform and } \\
\text { Hilbert transform to obtain the envelope of the signal. } \\
\text { (2) Fault diagnosis classification through measured features } \\
\text { (Eigenvector changes). }\end{array}$ & Transient & 100 & - & 100 & $100^{2}$ \\
\hline & $\begin{array}{l}\text { (1) Signal decomposition by means of empirical mode } \\
\text { decomposition method. }\end{array}$ & Transient & 98.2 & 99.7 & 98.2 & - \\
\hline $\begin{array}{l}\text { Valles-Novo et al. } \\
\text { [5] }\end{array}$ & $\begin{array}{l}\text { (2) Standard deviation of zero crossings and the time } \\
\text { between successive zero crossings of the decompositions for } \\
\text { fault diagnosis classification. }\end{array}$ & Steady & 98.2 & 98.2 & 98.5 & - \\
\hline Proposal & (1) Shannon entropy for statistical feature extraction. & Transient & 100 & 95 & 100 & $100^{2}$ \\
\hline Propos & (2) Fault diagnosis classification through $K$-means method. & Steady & 100 & 100 & 100 & $100^{2}$ \\
\hline
\end{tabular}

HLT: healthy condition; HBRB: half broken rotor bar; 1BRB: one broken rotor bar; MBRB: multiple broken rotor bars, where 2 means two broken bars, 3 means three broken bars, and 5 means five broken bars.

$A z$ vibration signals is used, it is found that $A x$ and $A z$ provide enough information to diagnose the treated fault, which simplifies even more the computational cost of the proposal.

The FPGA implementation as SoC solution for online and continuous monitoring is also developed. In general, a low consumption of FPGA resources with a maximum of $11.67 \%$ is obtained. This is possible since the $K$-centroids are computed offline and in the implementation stage only a search for the nearest cluster through the Euclidian distance is required. It is worth noting that the same methodology can diagnose the faults during both transient and steady regimens with a high accuracy; therefore, the processor cores can be reused with an only change in the selected $K$-centroids.

In a future work, different load conditions in both states will be explored in order to improve the usefulness and applicability of the proposed methodology. Besides that, other mechanical and electrical faults will be analyzed using the proposed methodology; in fact, other signals such as current or temperature will be also explored in order to obtain unique and reliable patterns for each condition.

\section{Competing Interests}

The authors declare that they have no competing interests.

\section{References}

[1] P. Zhang, Y. Du, T. G. Habetler, and B. Lu, "A survey of condition monitoring and protection methods for medium-voltage induction motors," IEEE Transactions on Industry Applications, vol. 47, no. 1, pp. 34-46, 2011.

[2] M. Hernandez-Vargas, E. Cabal-Yepez, and A. Garcia-Perez, "Real-time SVD-based detection of multiple combined faults in induction motors," Computers and Electrical Engineering, vol. 40, no. 7, pp. 2193-2203, 2014.

[3] R. J. Romero-Troncoso, A. Garcia-Perez, D. Morinigo-Sotelo, O. Duque-Perez, R. A. Osornio-Rios, and M. A. Ibarra-Manzano, "Rotor unbalance and broken rotor bar detection in inverter-fed induction motors at start-up and steady-state regimes by highresolution spectral analysis," Electric Power Systems Research, vol. 133, pp. 142-148, 2016.

[4] J. A. Antonino-Daviu, M. Riera-Guasp, M. Pineda-Sanchez, and R. B. Pérez, "A critical comparison between DWT and 
Hilbert-Huang-based methods for the diagnosis of rotor bar failures in induction machines," IEEE Transactions on Industry Applications, vol. 45, no. 5, pp. 1794-1803, 2009.

[5] R. Valles-Novo, J. d. j. Rangel-Magdaleno, J. M. RamirezCortes, H. Peregrina-Barreto, and R. Morales-Caporal, "Empirical mode decomposition analysis for broken-bar detection on squirrel cage induction motors," IEEE Transactions on Instrumentation and Measurement, vol. 64, no. 5, pp. 1118-1128, 2015.

[6] Y.-H. Kim, Y.-W. Youn, D.-H. Hwang, J.-H. Sun, and D.S. Kang, "High-resolution parameter estimation method to identify broken rotor bar faults in induction motors," IEEE Transactions on Industrial Electronics, vol. 60, no. 9, pp. 41034117, 2013.

[7] J. Kurek and S. Osowski, "Support vector machine for fault diagnosis of the broken rotor bars of squirrel-cage induction motor," Neural Computing and Applications, vol. 19, no. 4, pp. 557-564, 2010.

[8] S.-R. Huang, K.-H. Huang, K.-H. Chao, and W.-T. Chiang, "Fault analysis and diagnosis system for induction motors," Computers \& Electrical Engineering, 2016.

[9] P. K. Kankar, S. C. Sharma, and S. P. Harsha, "Rolling element bearing fault diagnosis using wavelet transform," Neurocomputing, vol. 74, no. 10, pp. 1638-1645, 2011.

[10] A. Bellini, A. Yazidi, F. Filippetti, C. Rossi, and G.-A. Capolino, "High frequency resolution techniques for rotor fault detection of induction machines," IEEE Transactions on Industrial Electronics, vol. 55, no. 12, pp. 4200-4209, 2008.

[11] A. Garcia-Perez, J. P. Amezquita-Sanchez, A. DominguezGonzalez, R. Sedaghati, R. Osornio-Rios, and R. J. RomeroTroncoso, "Fused empirical mode decomposition and wavelets for locating combined damage in a truss-type structure through vibration analysis," Journal of Zhejiang University: Science A, vol. 14, no. 9, pp. 615-630, 2013.

[12] M. Barakat, M. El Badaoui, and F. Guillet, "Hard competitive growing neural network for the diagnosis of small bearing faults," Mechanical Systems and Signal Processing, vol. 37, no. 1-2, pp. 276-292, 2013.

[13] Z. Liu, H. Cao, X. Chen, Z. He, and Z. Shen, "Multi-fault classification based on wavelet SVM with PSO algorithm to analyze vibration signals from rolling element bearings," Neurocomputing, vol. 99, pp. 399-410, 2013.

[14] J. Rangel-Magdaleno, H. Peregrina-Barreto, J. Ramirez-Cortes, R. Morales-Caporal, and I. Cruz-Vega, "Vibration analysis of partially damaged rotor bar in induction motor under different load condition using DWT,' Shock and Vibration, vol. 2016, Article ID 3530464, 11 pages, 2016.

[15] L. Zhang, L. Zhang, J. Hu, and G. Xiong, "Bearing fault diagnosis using a novel classifier ensemble based on lifting wavelet packet transforms and sample entropy," Shock and Vibration, vol. 2016, Article ID 4805383, 13 pages, 2016.

[16] R. Valles-Novo, J. D. J. Rangel-Magdaleno, J. M. RamirezCortes, H. Peregrina-Barreto, and R. Morales-Caporal, "Empirical mode decomposition analysis for broken-bar detection on squirrel cage induction motors," IEEE Transactions on Instrumentation and Measurement, vol. 64, no. 5, pp. 1118-1128, 2015.

[17] V. Climente-Alarcon, J. A. Antonino-Daviu, M. Riera-Guasp, and M. Vlcek, "Induction motor diagnosis by advanced notch FIR filters and the wigner-ville distribution," IEEE Transactions on Industrial Electronics, vol. 61, no. 8, pp. 4217-4227, 2014.
[18] A. L. Martinez-Herrera, L. M. Ledesma-Carrillo, M. LopezRamirez, S. Salazar-Colores, E. Cabal-Yepez, and A. GarciaPerez, "Gabor and the Wigner-Ville transforms for broken rotor bars detection in induction motors," in Proceedings of the 24th International Conference on Electronics, Communications and Computers (CONIELECOMP '14), pp. 83-87, IEEE, Puebla, Mexico, February 2014.

[19] S. Pan, T. Han, A. C. C. Tan, and T. R. Lin, "Fault diagnosis system of induction motors based on multiscale entropy and support vector machine with mutual information algorithm," Shock and Vibration, vol. 2016, Article ID 5836717, 12 pages, 2016.

[20] N. Saravanan and K. I. Ramachandran, "Incipient gear box fault diagnosis using discrete wavelet transform (DWT) for feature extraction and classification using artificial neural network (ANN)," Expert Systems with Applications, vol. 37, no. 6, pp. 4168-4181, 2010.

[21] G. F. Bin, J. J. Gao, X. J. Li, and B. S. Dhillon, "Early fault diagnosis of rotating machinery based on wavelet packetsempirical mode decomposition feature extraction and neural network," Mechanical Systems and Signal Processing, vol. 27, no. 1, pp. 696-711, 2012.

[22] R. J. Romero-Troncoso, R. Saucedo-Gallaga, E. Cabal-Yepez et al., "FPGA-based online detection of multiple combined faults in induction motors through information entropy and fuzzy inference," IEEE Transactions on Industrial Electronics, vol. 58, no. 11, pp. 5263-5270, 2011.

[23] D. P. Winston and M. Saravanan, "Single parameter fault identification technique for DC motor through wavelet analysis and fuzzy logic," Journal of Electrical Engineering and Technology, vol. 8, no. 5, pp. 1049-1055, 2013.

[24] Y. Sharma and P. Kaur, "Detection and extraction of brain tumor from MRI images using K-means clustering and watershed algorithms," International Journal of Computer Science Trends and Technology, vol. 3, no. 2, pp. 32-38, 2015.

[25] H. Qarib and H. Adeli, "A new adaptive algorithm for automated feature extraction in exponentially damped signals for health monitoring of smart structures," Smart Materials and Structures, vol. 24, no. 12, Article ID 125040, 2015.

[26] H. Zhou, Y. C. Soh, and X. Wu, "Integrated analysis of CFD data with $\mathrm{K}$-means clustering algorithm and extreme learning machine for localized HVAC control," Applied Thermal Engineering, vol. 76, pp. 98-104, 2015.

[27] C. E. Shannon, "A mathematical theory of communication," The Bell System Technical Journal, vol. 27, no. 3, pp. 379-423, 1948.

[28] Y. Wu, Y. Zhou, G. Saveriades, S. Agaian, J. P. Noonan, and P. Natarajan, "Local Shannon entropy measure with statistical tests for image randomness," Information Sciences, vol. 222, pp. 323-342, 2013.

[29] H. H. Bafroui and A. Ohadi, "Application of wavelet energy and Shannon entropy for feature extraction in gearbox fault detection under varying speed conditions," Neurocomputing, vol. 133, pp. 437-445, 2014.

[30] T.-K. Lin and J.-C. Liang, "Application of multi-scale (cross) sample entropy for structural health monitoring," Smart Materials and Structures, vol. 24, no. 8, Article ID 085003, 2015.

[31] A. Lay-Ekuakille, P. Vergallo, G. Griffo et al., "Entropy index in quantitative EEG measurement for diagnosis accuracy," IEEE Transactions on Instrumentation and Measurement, vol. 63, no. 6, pp. 1440-1450, 2014.

[32] E. Cabal-Yepez, R. J. Romero-Troncoso, A. Garcia-Perez, R. A. Osornio-Rios, and R. Alvarez-Salas, "Multiple fault detection 
through information entropy analysis in ASD-fed induction motors," in Proceedings of the 8th IEEE Symposium on Diagnostics for Electrical Machines, Power Electronics \& Drives (SDEMPED '11), pp. 391-396, Bologna, Italy, September 2011.

[33] E. Cabal-Yepez, R. D. J. Romero-Troncoso, A. Garcia-Perez, and C. Rodriguez-Donate, "Novel hardware processing unit for dynamic on-line entropy estimation of discrete time information," Digital Signal Processing, vol. 20, no. 2, pp. 337-346, 2010.

[34] T. Velmurugan, "Performance based analysis between k-Means and Fuzzy C-Means clustering algorithms for connection oriented telecommunication data," Applied Soft Computing Journal, vol. 19, pp. 134-146, 2014.

[35] C. T. Yiakopoulos, K. C. Gryllias, and I. A. Antoniadis, "Rolling element bearing fault detection in industrial environments based on a K-means clustering approach," Expert Systems with Applications, vol. 38, no. 3, pp. 2888-2911, 2011.

[36] R. Andraka, "A survey of CORDIC algorithms for FPGA based computers," in Proceedings of the ACMSIGDA 6th International Symposium on Field Programmable Gate Arrays (FPGA '98), pp. 191-200, Monterey, Calif, USA, February 1998.

[37] D. Matić, F. Kulić, M. Pineda-Sánchez, and I. Kamenko, "Support vector machine classifier for diagnosis in electrical machines: application to broken bar," Expert Systems with Applications, vol. 39, no. 10, pp. 8681-8689, 2012.

[38] A. M. Da Silva, R. J. Povinelli, and N. A. O. Demerdash, "Rotor bar fault monitoring method based on analysis of air-gap torques of induction motors," IEEE Transactions on Industrial Informatics, vol. 9, no. 4, pp. 2274-2283, 2013.

[39] G. Georgoulas, I. P. Tsoumas, J. A. Antonino-Daviu et al., "Automatic pattern identification based on the complex empirical mode decomposition of the startup current for the diagnosis of rotor asymmetries in asynchronous machines," IEEE Transactions on Industrial Electronics, vol. 61, no. 9, pp. 4937-4946, 2014.

[40] H. Keskes, A. Braham, and Z. Lachiri, "Broken rotor bar diagnosis in induction machines through stationary wavelet packet transform and multiclass wavelet SVM," Electric Power Systems Research, vol. 97, pp. 151-157, 2013.

[41] J. J. Rangel-Magdaleno, H. Peregrina-Barreto, J. M. RamirezCortes, P. Gomez-Gil, and R. Morales-Caporal, "FPGA-based broken bars detection on induction motors under different load using motor current signature analysis and mathematical morphology," IEEE Transactions on Instrumentation and Measurement, vol. 63, no. 5, pp. 1032-1040, 2014.

[42] A. Menacer, M. Boumehraz, and H. Cherif, "DWT and Hilbert transform for broken rotor bar fault diagnosis in induction machine at low load," Energy Procedia, vol. 74, pp. 1248-1257, 2015. 


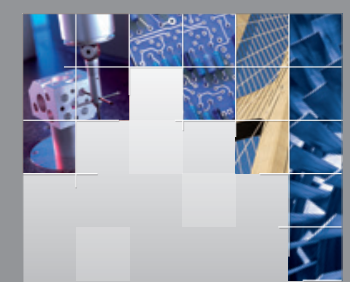

\section{Enfincering}
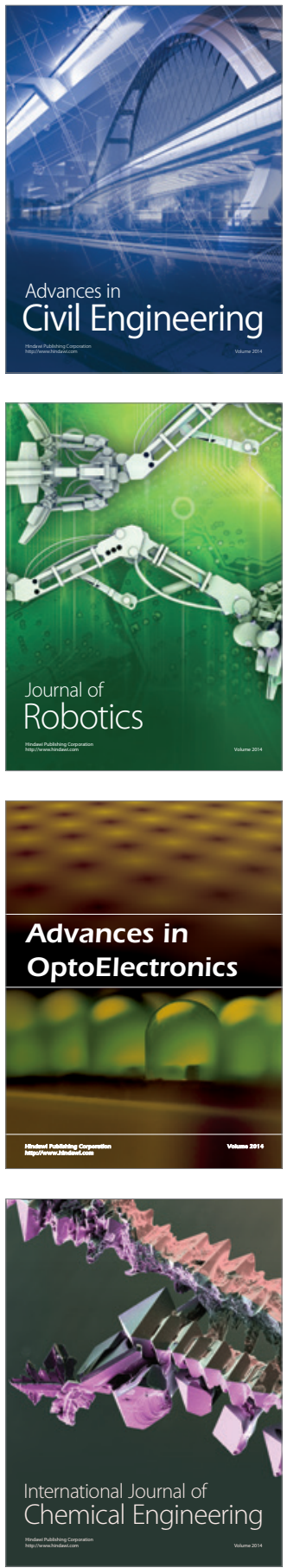

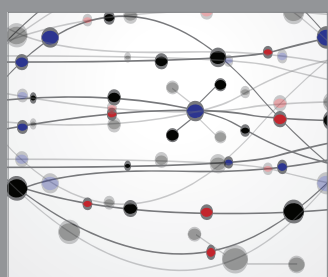

The Scientific World Journal

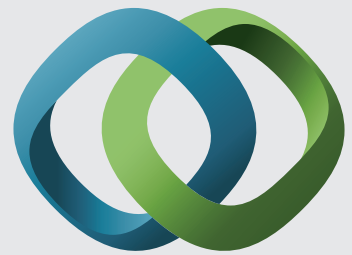

\section{Hindawi}

Submit your manuscripts at

http://www.hindawi.com
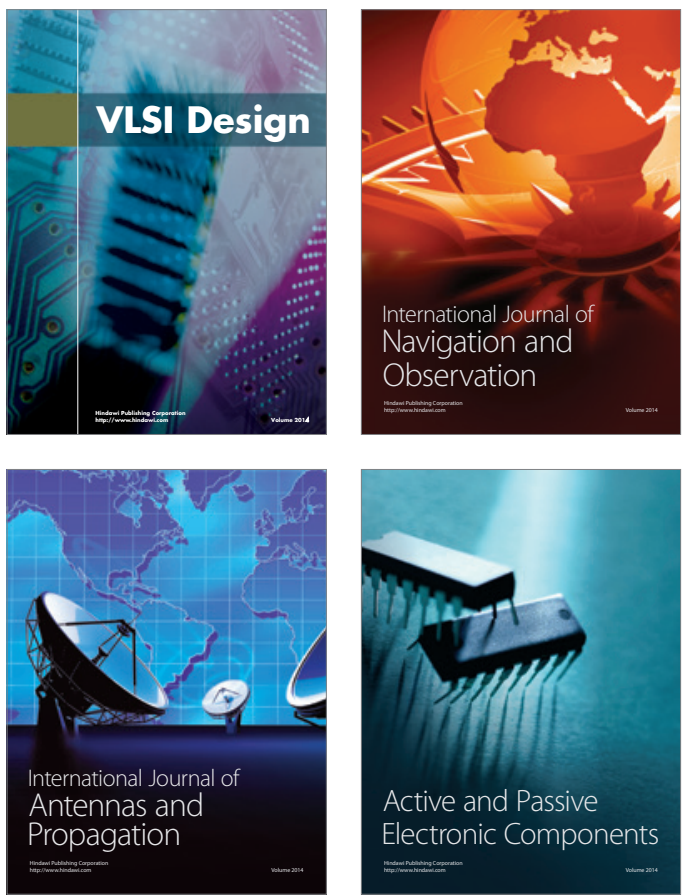
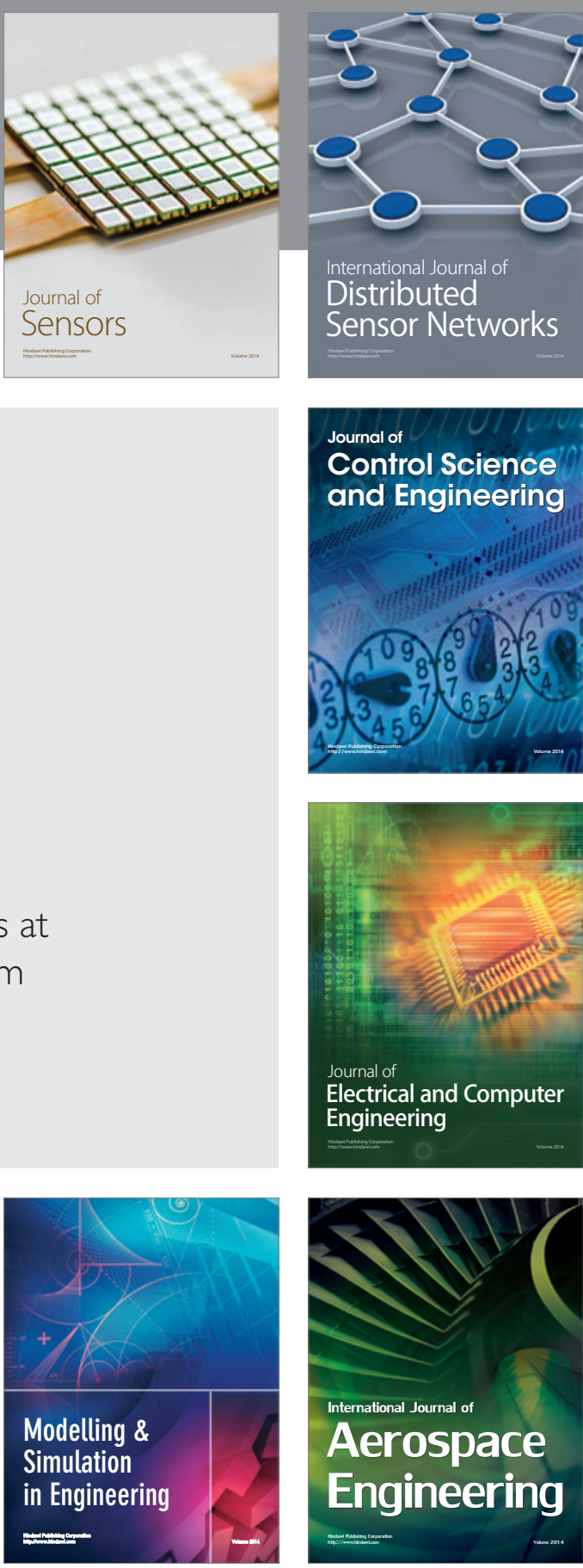

International Journal of

Distributed

Sensor Networks

Journal of

Control Science

and Engineering
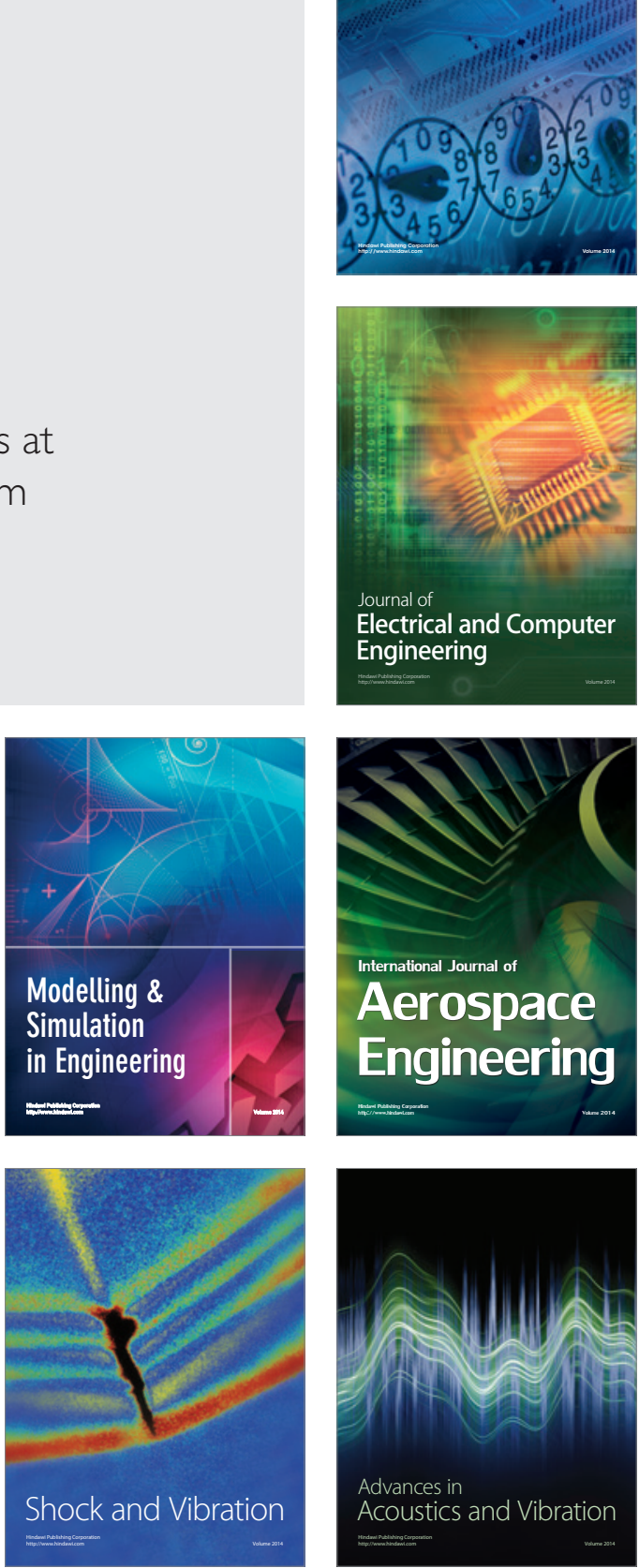